\title{
Self-Effication As the Determinants For the Intention of Entrepreneurship
}

Rachma Rizqina Mardhotillah ${ }^{1}$, Denis Fidita Karya ${ }^{2}$, Candraningrat ${ }^{3}$

1,2Nahdlatul Ulama University of Surabaya, Indonersia, ${ }^{3}$ Dinamika University, Indonesia

\begin{tabular}{|c|c|}
\hline ARTICLE INFO & ABSTRACT \\
\hline $\begin{array}{l}\text { Received November } 2020 \\
\text { Accepted November } 2020 \\
\text { Published December } 2020\end{array}$ & $\begin{array}{l}\text { This examination intends to decide: (1) The degree of self- } \\
\text { adequacy of undergraduate management study programs in } \\
\text { Surabaya, (2) The degree of enterprising expectations of } \\
\text { undergraduate management study programs in Surabaya, (3) }\end{array}$ \\
\hline $\begin{array}{l}\text { Keywords: Intention of } \\
\text { Entrepreneurship, Self- } \\
\text { Efficacy. }\end{array}$ & $\begin{array}{l}\text { The impact of self-viability on undergraduate management } \\
\text { study programs in Surabaya. The number of population in this } \\
\text { examination is the undergraduate management study programs } \\
\text { in Surabaya. The testing system utilizes Proportionate Stratified } \\
\text { Random Sampling and acquired an example of } 167 \\
\text { undergraduate management study programs in Surabaya. The } \\
\text { instrument preliminary utilized master judgment and proceeded } \\
\text { with preliminaries on } 30 \text { undergraduate management study } \\
\text { programs in Surabaya. Validity test in this research utilizes the } \\
\text { Product Moment connection method from Pearson. Unwavering } \\
\text { quality test utilizing the Cronbach Alpha. Information gathering } \\
\text { utilizes a survey that is dispersed straightforwardly and through } \\
\text { electronic media. The investigation essential testing incorporates } \\
\text { typicality test and linearity test. The information investigation } \\
\text { method utilized is straightforward relapse to test theories. }\end{array}$ \\
\hline
\end{tabular}

\section{Introduction}

The issue of joblessness is one of the serious issues in the field of work in Indonesia. The issue of joblessness has consistently been in the open spotlight in light of the fact that the joblessness rate in Indonesia is expanding step by step [1]. An undeniably dismal reality is that the informed joblessness rate in Indonesia is very huge. This is terrible in light of the fact that when seen from the capacities and ability controlled by understudies, the individual ought to have the option to find a new line of work or even open their own occupations [2]. The International Labor Organization, the International Labor Organization (ILO) takes note of that the quantity of jobless individuals in Indonesia has expanded. Presently it arrives at 6.25\% until August 2013. The way that can be uncovered that the quantity of jobless in Indonesia keeps on expanding [3]. The quantity of the workforce isn't relative to the quantity of occupations. This outcomes in serious challenge for work. The gatherings who can't contend are eventually jobless.

Beginning from the present conditions, the calling as a business visionary is by all accounts one of the correct arrangements [4]. Individuals never again rely upon accessible employments, however begin considering approaches to make their own 
occupations [5]. The administration likewise started to forcefully dispatch a national innovative development. The Directorate General of Higher Education Ministry of Education and Culture (Dirjen Dikti Kemendikbud) additionally underpins the advancement of business enterprise programs for understudies. The Ministry of Education and Culture's Director General of Higher Education has propelled the Entrepreneurial Student Program (PMW) to be actualized and created by open and private colleges. PMW expects to give information, abilities and dispositions or enterprising soul dependent on science and innovation to understudies with the goal that they can change the outlook of occupation searchers into employment makers. The program is likewise expected to diminish joblessness for tertiary training graduates.

Want or innovative expectations that exist in an individual surely does not show up immediately but rather through a few phases [6]. An individual does not begin a business by reflex, yet they do it deliberately. Hypothesis Planned of Behavior displays that enterprising goals have stages. Before the goal emerges at first in the person there is inspiration or want to make something, this urges the person to succeed [7]. These individuals have the requirement for high achievers who are made a decision to be fearless in settling on the choices they have made. Likewise, the presence of a high want to prevail with regards to accomplishing something will shape high fearlessness and poise (locus of control) of the person [8]. In the event that somebody has an inside locus of control, at that point the conviction will develop that he can control the earth with the capacity he must almost certainly accomplish what he needs [9]. The following stage that is shaped is self-adequacy (self viability) where people with high self-adequacy will have a high goal to advance themselves through business [4].

Want of business (innovative expectations) among understudies is still appalling, on the grounds that the enterprising aims of understudies can be a wellspring of birth of future business people [6]. One significant factor in making business is aim. Expectation or aim is the earnestness of somebody to do business exercises [7]. The more noteworthy the business visionary's expectation, the better it will be to begin a business. The aim of somebody who is offset with trust in himself will goodly affect the introduction of new business visionaries in order to make openings or work [9].

Through expectation, one can foresee the moves that will be made. In the event that the goals of business enterprise are low, at that point innovative conduct can likewise be conceivable low. Along these lines, investigate should be done on the effect of self-efficacy on student entrepreneurial intentions for undergraduate management study programs in Surabaya.

\section{Research Methods}

This research is an ex-post facto type of research because this research reveals existing data or events without changing or manipulating the variables or samples studied. Ex-post facto research was conducted to examine events that had occurred. This research is a causal study because it intends to reveal the effect of the independent variables on the dependent variable. This research uses a quantitative approach, meaning that all of its data is expressed in numbers and its analysis is based on statistical analysis. This study uses a sample as research respondents. The study population was 
all students of undergraduate management study programs in Surabaya amounting to 303. The reason for choosing the class of 2018- 2019 was because students in the class had taken entrepreneurship courses which meant that the student had sufficient knowledge about entrepreneurship and was able to understand contents of statements in the instrument. Determination of the sample in this study using proportional stratified random sampling technique. From the table of the number of samples according to Isaac and Michael it is known that from a population of 303 with an error rate of 5\%, a total sample of 167 students is known.

Data analysis: In view of the aftereffects of the examination note that the estimation of the Kaiser-Meyer-Olkin Measure of Sampling Adequacy (KMO MSA) is more noteworthy than 0.50 which is equivalent to 0.783 , this demonstrates the current information is attainable for investigation, while the consequences of the Bartlett's Test of Sphericity are gotten the essentialness level is 0,000, which implies that between factors there is a relationship (criticalness $<0.05$ ), along these lines it tends to be reasoned that every current variable can be additionally broke down in light of the fact that they meet the criteria. The dependability test outcomes demonstrated that all inquiry things of the three factors concentrated were solid since they had a Cronbach Alpha value $>0.70$. Hence, the appropriate responses from respondents as per reality and the following stage can be played out different relapse investigation.

\section{Result and Discussion}

Theoretical framework and hypotheses: Overview of Entrepreneurship: The theme of business is an interesting issue, since it is a test for the Indonesian individuals to create innovative frames of mind and capacities. Business enterprise is the way toward making something different utilizing time and exercises joined by capital and hazard and getting prizes and fulfillment and individual flexibility. Enterprise is frequently connected with the procedure, arrangement or development of another business that is situated to gainfulness, esteem creation, and the development of new items or administrations that are interesting and inventive.

Enterprise is a procedure of applying imagination and advancement in taking care of issues and discovering chances to improve life (business). In accordance with this conclusion, business enterprise is a procedure of making something (new creation) and making something other than what's expected from what as of now exists (development), the point is to accomplish singular welfare and increased the value of the network. Entrepreneurship means joining individual character, fund and assets. Along these lines, business is a vocation or profession that must be adaptable and innovative, ready to design, go out on a limb, choices and activities to accomplish objectives. Business visionaries are individuals who set out to face dangers and like difficulties. Business people (business visionaries) are individuals who are bold in going out on a limb to start organizations in different chances. In view of a portion of these suppositions, it very well may be reasoned that the innovative Adala $h$ individuals who have the fortitude to go ou $\mathrm{t}$ on a limb to begin a business so as to accomplish gainfulness. A business visionary will use existing assets to be used in his business. 
Advantages and Weaknesses of being an Entrepreneur: Basic leadership turns into a business person has constructive and pessimistic sides which can be called as focal points and disservices of being a business person. The advantages of being a business visionary are 1) There are chances to accomplish your own ideal objectives; 2 ) There are chances to exhibit one's capacities and potential in full; 3) open doors for most extreme advantages and advantages; 4) Opportunities are available to assist the network with solid endeavors and 5) Open the chance to turn into a supervisor. There are a few shortcomings in business enterprise, specifically 1) Obtain dubious salary, and accept different dangers; 2) Work hard and work extended periods of time; 3) An amazing nature is still low until his business succeeds, in light of the fact that he needs to cut back; 4) His obligations are progressively huge, numerous choices that he should not ace the issues he faces.

Shortcomings in enterprise as indicated to be specific 1) Personal penance. At the outset, business visionaries, needed to work extended periods and were occupied; 2) The weight of obligation. Business visionaries must deal with all business capacities, both promoting, budgetary, individual, just as obtainment and preparing and 3) The little net revenues and the huge likelihood of disappointment. Business people utilize their very own wellspring of assets, the benefit/net revenue acquired is generally little. In light of a portion of these assessments, it tends to be reasoned that the advantages of being a business visionary are having the chance to accomplish their very own ideal objectives, helping the network with genuine organizations, the chance to be a supervisor, allowed to do anything on their business, roused to succeed, allowed to deal with their own accounts, and get benefit. The shortcomings of being a business person are questionable salary, long working hours, enormous duties that spread all things, toward the start of the endeavor benefit is little and has the likelihood of disappointment.

Entrepreneurial Characteristics: The idea of Need for Achievement, hereinafter contracted (N-Ach), which is characterized as a character infection that makes an individual need to improve and push ahead, continually considering improving, and have a practical objective by taking hazardous activities that have truly been determined. Mc Clelland subtleties the attributes of the individuals who have high N-Ach as pursues 1) Prefer work with sensible dangers; 2 ) Work harder in assignments that require mental capacities; 3) Do not work more earnestly on the grounds that there is cash consequently; 4) Want to work in circumstances where individualaccomplishment can be gotten; 5) Demonstrate better execution in conditions that give positive clear input and 6) Tend to think into the future and have long haul thinking.

There are ten fundamental frames of mind (character) of business, in particular 1) (visionary) that can see a long ways ahead, consistently do the best in the present, while envisioning a superior future. A business person will in general be imaginative and creative; 2) Positive, which is to help a business visionary consistently think great, not be enticed to consider things that are negative, so he can transform difficulties into circumstances and consistently consider something greater; 3 ) Confident (certainty), this frame of mind will direct somebody in each choice and step. Certainty does not generally say "Yes" yet additionally sets out to state "No" if fundamental; 4) Genuine, a business person must have thoughts, feelings and permit his very own model. Not that he should 
make something genuinely new, he could have sold an item that is equivalent to another, however he should give included worth or new; 5) Goal Oriented (objective focused), constantly situated to the assignment and results. A business visionary needs to consistently need to consistently accomplish, benefit situated, driving forward, buckling down, and order to accomplish something that has been set; 6) Persistent (hold the test), must go ahead, have vitality, and uplifted spirits, never surrender, not effectively debilitated, and on the off chance that you fall up quickly get back up; 7) Ready to confront a hazard, the most serious hazard is a business disappointment and cash runs out. Prepared to face hazard, rivalry, value vacillations, now and again benefit or misfortune, things not sold or no oder. Must be looked with certainty. He makes evaluations and cautious arranging, with the goal that difficulties and dangers can be limited; 8) Creative (inventive mengap openings), openings are consistently there and go before us. Sharp mentality isn't just ready to see openings, yet additionally ready to make openings; 9) Healthy Competitor (being a decent contender). In the event that you set out to enter the business world, you should set out to enter the universe of rivalry. Rivalry ought not be upsetting, yet it must be believed to make us advance and think well. An uplifting mentality endures and exceed expectations in the challenge; and 10) Democratic pioneer (just pioneer), has a popularity based administration, ready to be a model and motivation for other people. Ready to satisfy others, without losing bearing, and objectives, and ready to be with others without losing their own personality.

In light of a portion of these feelings, it creates the impression that there are likenesses of conclusions between one master with another master. Accordingly, it very well may be presumed that the attributes of business visionaries who are effective are happy to go out on a limb, energy and diligent work, think long haul, have an awareness of other's expectations for his endeavors, having what it takes to handle a business, and a high certainty for progress.

Overview of Entrepreneurship Intention: Pioneering goals can be translated as the way toward discovering data that can be utilized to accomplish the targets of shaping a business. Aim is a segment in a person that alludes to the craving to play out specific practices. Aim is a major component that can clarify a conduct. As an indicator of conduct, goal is viewed as an imperative inspiration when somebody will submit certain practices. Aim is an effective indicator of conduct since it spans frames of mind and conduct. Aim has been demonstrated to be the best indicator of innovative conduct. In view of a portion of these suppositions, it tends to be presumed that goal is a significant marker that can be utilized to foresee an adjustment in conduct later on the grounds that aim has a cozy association with the ideal conduct. Pioneering expectation is characterized as the longing or goal that exists in an individual to show innovative conduct that can be seen from the goal of people to have the option to go out on a limb, exploit openings, become an inventive and free individual and have the option to process existing assets.

Aspects for Measuring Entrepreneurial Intention: One model of intention development formulated by Ajzen is Theory of Planned Behavior (TPB). The core of TPB remains in the behavioral intention factor as presented in the following figure. TPB identified three factors that preceded intention. Two factors reflect the perceived desire 
to perform a behavior, namely: personal attitude towards personal behav-ioral results and perceived social norms. The third factor is perceived behavioral control (perceived feasibil-ity), reflecting the perception that behavior is personally controlled. Based on this description, then in this study, there are 3 aspects to measuring entrepreneurial intentions, namely attitudes toward behavior, subjective norms and behavior control. These three aspects are also used as indicators of entrepreneurial intentions.

Factors that influence entrepreneurship intentions: Entrepreneurial intentions are influenced by three things namely demographic factors and individual backgrounds; personality factors (personality); and finally that several studies support that demographic factors influence a person's desire to become an entrepreneur. These demographic factors include gender, age, education and one's experience. Women are more likely to have low entrepreneurial intentions compared to men. The second factor is a person's personality characteristics. The concept of need for achievement as a psychological motive. Furthermore, the need for achievement as one of the characteristics of one's personality that will encourage someone to have entrepreneurial intentions. Someone who has a need for presenting has a tendency to persevere and even is compelled to fulfill the task entrusted to him. Self-efficacy factors namely that selfefficacy affects the intentions of one's entrepreneurship.

The third factor is the contextual element. Contextual elements which include three environmental factors that are believed to influence entrepreneurs are their access to capital, information and the quality of social networks they have, which is then called instrument readiness. Based on some of the opinions and results of these studies, it can be concluded that there are three factors that influence entrepreneurial intentions. These three factors are demographic factors, personality factors, and contextual element factors. Demographic factors include gender, age, education, background and experience of a person; personality factors include the need for achievement, locus of control and self efficacy; and contextual elements include access to capital, information, and network.

Overview of Self-Efficacy: Self-efficacy is the belief that someone can master a situation and produce various positive results. Self- efficacy helps people in various situations that are unsatisfactory and encourages them to believe that they can succeed. Self-efficacy is related to a number of positive developments in one's life. Positive selfefficacy is the belief to be able to perform the intended behavior. Without self-efficacy (certain beliefs that are very situational), people even want to do a behavior. Self-efficacy determines whether someone will exhibit certain behaviors, how strong that person can be survive when faced with failure or difficulties, and how success or failure in a particular task affects fu-ture behavior.

Self-efficacy is measured by the self-efficacy scale. Indicator in measuring selfefficacy namely confidence in the ability to manage the business and leadership in starting a business. Based on these opinions, it can be concluded that self-efficacy is a belief in one's abilities. If someone is not sure they can produce the results they want, they have little motivation to act. Someone who has high self-efficacy has the potential to be able to change events in his environment, will be more likely to act and more likely to be successful than people who have low self-efficacy. 
Factors that affect Self-Efficacy: Self-efficacy can be obtained, improved, or reduced through one or a combination of four sources. The four sources are 1) The experience of mastering something (mastery experiences); 2) Social modeling; 3) Social persuasion; and 4) Physical and emotional conditions. Self-efficacy can be obtained, changed, increased or reduced, through one or a combination of the four sources. The most influential source on one's self-efficacy is his past experience, while other sources have an effect but only in certain situations.

Framework of thinking: Intention is a strong predictor of an action. Someone who has entrepreneurial intentions has more entre- preneurial readiness than someone who has no intention. The intention of entrepreneurship can be a meas-ure of a person's actions, whether he will choose a career to be an entrepreneur or not an entrepreneur. The intention of entrepreneurship is influenced by three things, namely demographic factors, personality, and contextual elements. Demographic factors include a person's sex, age, education, background, and experi-ence; personality factors include the need for achievement, locus of control and self efficacy; and contextual elements include access to capital, information and networks. Self-efficacy is part of the personality factor that influences one's entrepreneurial intentions. Self-efficacy is a belief in one's abilities. Someone who has high self-efficacy in terms of entrepreneurship will have a strong desire to entrepreneurship, and vice versa. Someone who has low self-efficacy, also has low entrepre-neurial desire. This means that self-efficacy is a factor that influences entrepreneurial intentions.

The results of research on the level of student self-efficacy are in the medium category. This is indicated by the number of research respondents who answered the most in the medium category of 113 students $(67.66 \%)$. Then the number of students who answered the high category was 42 students $(27.54 \%)$, and the number of students who answered the low category was 8 students $(4.80 \%)$. Based on these data, it can be seen that not all students have high levels of self-efficacy so there are still students who have entrepreneurial intentions that are not yet high.

The results of research on student entrepreneurial intentions are in the medium category. This is indicated by the number of research respondents who answered the most in the medium category of 93 students (55.69\%). Then the number of students who answered the high category was 71 students $(42.51 \%)$, and the number of students who answered the low category was 3 students $(1.80 \%)$. Based on these data, it can be seen that not all students have a high level of entrepreneurial intentions so there are still students who do not wish to become entrepreneur.

\section{Conclusion}

Based on the research results obtained as a whole, the following conclusions can be drawn:

1. The level of self-efficacy of students of undergraduate management study programs in Surabaya is included in the moderate category (68\%).

2. The level of entrepreneurial intention of undergraduate management study programs in Surabaya in the medium category (59\%). 
3. There is a positive and significant effect of self-efficacy on undergraduate management study programs in Surabaya as indicated by rxy is 0.655 and $\mathrm{r} 2 \mathrm{xy}=$ 0.429 , which means that the self-efficacy variable affects entrepreneurial intention of $42.9 \%$ and the value of entrepreneurship $\mathrm{t}$-value is greater than ttable at the $5 \%$ significance level that is $11,648>1,960$ with $\mathrm{N}=167$.

Implication:

1. The results of this study indicate that the tendency of self-efficacy variables are in the medium category. Based on this, in order to increase entrepreneurial intentions, students must increase their self-efficacy or self-confidence, especially in terms of entrepreneurship. So, high self-efficacy can increase student entrepreneurship intentions.

2. The results of this study indicate that there is a positive and significant effect between self-efficacy on the entrepreneurial intentions of undergraduate management study programs in Surabaya. The results of these studies can be used for students to improve their self-efficacy so that their intensities increase and eventually entrepreneurial behavior will be realized.

Suggestion: based on the results of the research discussion and conclusions above, suggestions can be given for Further Researchers that this study provides information that the variable of self-efficacy affects the student entrepreneurship intentions of $45.1 \%$. These results are still influenced by other variables by $54.9 \%$. Therefore, it is expected in the next research to reveal other factors (other variables) that influence the amount of student entrepreneurship intentions.

\section{References}

[1] F. S. Foltean, S. M. Trif, and D. L. Tuleu, "Customer Relationship Management Capabilities and Social Media Technology Use: Consequences on Firm Performance," J. Bus. Res., no. December 2017, pp. 1-13, 2018, doi: 10.1016/j.jbusres.2018.10.047.

[2] M. Bagheri and H. Khorrami, "Evaluating Human Factors in customer Relationship Management (Case Study: Private Banks of Shiraz City)," Procedia Econ. Financ., vol. 36, no. 16, pp. 363-373, 2016, doi: 10.1016/S2212-5671(16)30048$X$.

[3] M. Y. Anshori, D. F. Karya and F. Irhamni, “Team Learning, Team Performance, Entrepreneurial Intention, and Self-Regulated Learning in Entrepreneurship Education of UNUSA Students," International Council for Small Business World Conference Proceedings, 2019.

[4] Santoso, R., Shinta, R., \& Fianto, A. Y. A. (2019). Pengaruh Bauran Pemasaran Jasa terhadap Keputusan Berkunjung ke Wisata Bahari Jawa Timur. Jurnal MEBIS (Manajemen dan Bisnis), 4(2), 73-86.

[5] Fianto, A. Y. A. (2020). Satifaction as intervening for the antecedents of intention to revisit: Marinetourism context in East Java. Relasi: Jurnal Ekonomi, 16(1), 179207.

[6] Zhang, P., \& Cain, K. W. (2017). Reassessing the link between risk aversion and entrepreneurial intention: The mediating role of the determinants of planned 
behavior. International Journal of Entrepreneurial Behavior \& Research, 23(5), 793-811.

[7] Newbery, R., Lean, J., Moizer, J., \& Mohamed, H. (2018). Entrepreneurial identity formation during the initial entrepreneurial experience: The influence of simulation feedback and existing identity. Journal of Business Research, 85, 51-59.

[8] Smith, S., Hamilton, M., \& Fabian, K. (2019). Entrepreneurial drivers, barriers and enablers of computing students: Gendered perspectives from an Australian and UK university. Studies in Higher Education, 28, 1-14.

[9] Oguntimehin, Y., Abiodun, O., \& Oyejoke, O. (2017). The relationship between entrepreneur education and students' entrepreneurial intentions in Ogun State universities, Nigeria. British Journal of Education, 5(3), 9-20. 